\title{
Clinical Features and Prognosis of CD20 Negative Aggressive B-Cell Non-Hodgkins Lymphoma
}

\author{
Sumit Gaur, ${ }^{1}$ Osvaldo Padilla, ${ }^{2}$ and Zeina Nahleh ${ }^{1}$ \\ ${ }^{1}$ Department of Internal Medicine, Paul L Foster School of Medicine, Texas Tech University, 4800 Alberta Avenue, \\ El Paso, TX 79905, USA \\ ${ }^{2}$ Department of Pathology, Paul L Foster School of Medicine, Texas Tech University, 4800 Alberta Avenue, El Paso, TX 79905, USA
}

Correspondence should be addressed to Sumit Gaur; sumit.gaur@ttuhsc.edu

Received 3 October 2012; Accepted 16 December 2012

Academic Editor: Umberto Vitolo

Copyright (C) 2013 Sumit Gaur et al. This is an open access article distributed under the Creative Commons Attribution License, which permits unrestricted use, distribution, and reproduction in any medium, provided the original work is properly cited.

\begin{abstract}
Cluster designation (CD) 20 antigen is expressed on most B-cell lymphomas and serves as a therapeutic target for rituximab. A small minority of aggressive B-cell lymphomas, predominantly plasmablastic variants, do not express CD 20. We systematically reviewed all cases of aggressive B-cell lymphomas diagnosed at our institution over a period of 13 years. Of the 232 cases, 7 did not express CD 20. Five of these were plasmablastic lymphomas while two were unclassifiable B-cell lymphomas. While most of the plasmablastic lymphomas responded to chemotherapy, patients with unclassifiable lymphomas were primarily refractory or relapsed soon after chemotherapy.
\end{abstract}

\section{Introduction}

Diffuse large B cell lymphoma (DLBCL) is the most common histological subtype of non-Hodgkin's lymphoma in adults [1]. The addition of rituximab, a chimeric monoclonal antibody, to standard chemotherapy represents the most significant advance in the therapy of DLBCL over the last decade [2, 3]. Rituximab is directed against CD (cluster designation) 20, a cell surface glycoprotein, expressed on the surface of most B cells [4]. Identification of CD 20 expression thus aids in identifying the lymphoma as being of B-cell origin and in being potentially susceptible to rituximab.

A small minority of DLBCL do not express CD 20. Most of these are reported to be plasmablastic variants of DLBCL (primary effusion lymphomas, Anaplastic lymphoma kinase positive large B-cell lymphoma, and human immunodeficiency-virus associated plasmablastic lymphoma) and have been reported to have worse outcomes compared to other DLBCL [5-7].

We systematically reviewed the clinical and pathological features of all CD 20 negative DLBCL lymphoma patients diagnosed at our institution over the last 13 years.

\section{Methods}

The study received a waiver from the institutional review board for review of archival material and patient charts. All patients diagnosed with diffuse large B-cell lymphoma from January 1, 1998 to June 31, 2011 were identified through the tumor registry. Pathological and immunophenotypic findings were reviewed to identify patients with CD 20 negative DLBCL. All microscopic slides from these cases, including hematoxylin \& eosin and immunohistochemical stains were reviewed by the authors. Results of cytogenetic, fluorescent in situ hybridization (FISH) probes and polymerase chain reaction (PCR) analysis were reviewed when available. After confirming a diagnosis of CD 20 negative large B-cell lymphoma, we extracted the following clinical characteristics from the patient's medical records: age, sex, race, HIV status, other immunodeficiency states, Ann Arbor stage, bone marrow involvement, radiological findings, primary site of involvement (nodal versus extranodal), LDH level, choice of initial therapy, salvage therapy, date of diagnosis, and date of relapse. International prognostic index (IPI) was calculated for all patients. For HIV positive cases, CD 4 count and viral 


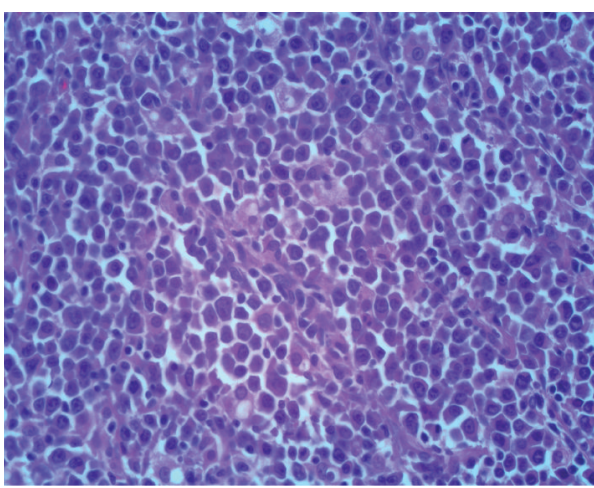

(a)

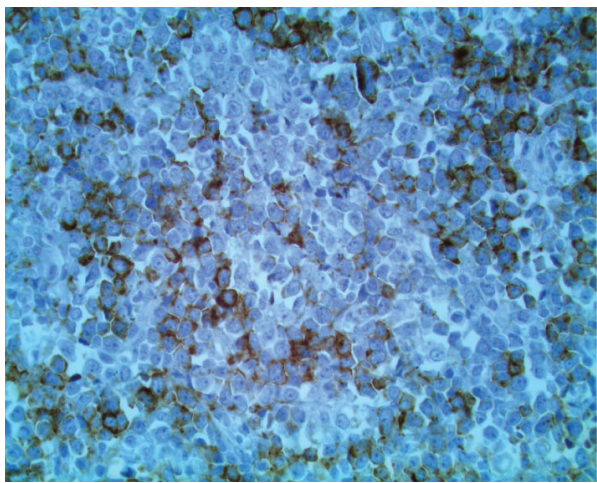

(c)

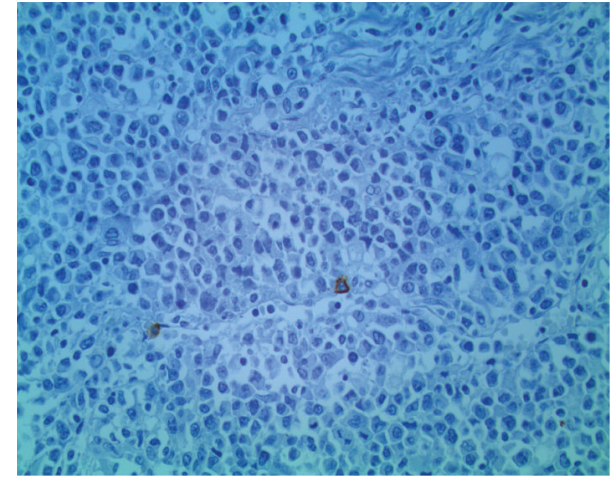

(b)

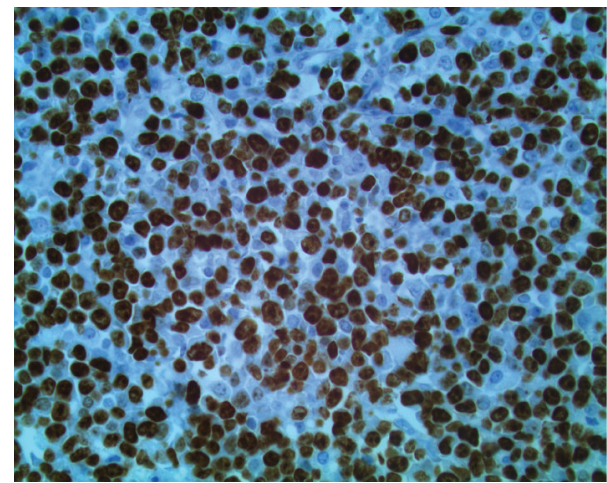

(d)

FIGURE 1: Hematoxylin-Eosin (H\&E) and immunohistochemical features of Patient 1. (a) H\&E shows medium to large-sized lymphoma cells with eccentric nuclei, heterochromatin at the edges of the nuclear membrane, and basophilic cytoplasm. These changes impart a plasmacytoid appearance. (b) Lymphoma does not stain for CD 20. (c) CD 138 stain demonstrates variable positive staining in significant number of neoplastic cells. (d) Ki-67 staining shows high proliferative index.

load was recorded. Survival data was obtained from the tumor registry.

\section{Results}

A total of 232 patients were diagnosed with diffuse large Bcell lymphoma at our institution over the last 13 years. Of these, seven had a CD 20 negative lymphoma (3\%). Clinical characteristic of these patients is shown in Table 1.

Five patients had plasmablastic DLBCL Figure 1. All five were males with HIV infection. Median age was 42 years (33-49). Median CD 4 count was $84 / \mu \mathrm{L}$ (45-250). The immunophenotype of these tumors is shown in Table 2. Three presented with a gastrointestinal primary (oropharynx, ileum, and anus). Four had stage IV disease, while one had stage IIE. LDH (lactate dehydrogenase) was elevated in 4 . Of the three samples tested for Epstein Barr virus (EBV), two were positive. FISH probes showed translocation involving MYC and immunoglobulin heavy chain gene $(8: 14)$ in both of these patients with EBV. Two patients were treated with R-CHOP (Rituximab, cyclophosphamide, doxorubicin, vincristine, and prednisone). Of these, 1 achieved a complete response which has lasted 3 years. The other died due to sepsis after the first cycle. Patient 3 was treated with six cycles of CHOP and remains in remission at 2 years. Patient 4 was treated with 8 cycles of hyper CVAD (hyperfractionated cyclophosphamide, vincristine, doxorubicin, and dexamethasone) alternating with high dose methotrexate and cytarabine. He achieved a complete response, which has lasted 2 years. All four patients who received chemotherapy also received antiretroviral treatment for HIV. Patient 5 died within a week of diagnosis due to suspected central nervous system involvement by lymphoma before receiving any specific treatment.

We also identified two patients with CD 20 negative high grade lymphoma, who did not have plasmablastic features. Patient 6 was a 44-year-old male who presented with a rectal and gastric mass, lymphomatous ascites, and bone-marrow involvement. He had stage IVB disease. IPI score was 3 . He did not have HIV infection. In addition polymerase chain reaction (PCR) ruled out infection with human herpes virus 8 . Biopsy of the rectal mass Figure 2 showed an aggressive B-cell lymphoma. Tumor cells stained positive for CD 79. They did not stain for CD 10 and CD 20. In addition, immunostains for CD 138, CD 30, and ALK were negative. Ki 67 was close to $100 \%$. Flow cytometry confirmed tumor cells to be positive for CD 79 and negative for CD 20. Karyotyping showed the following complex karyotype: 81-78,XY,+Y,+1, $+\operatorname{add}(1)(\mathrm{q} 42),+2,+3,+4,+4,+6,+6$, 


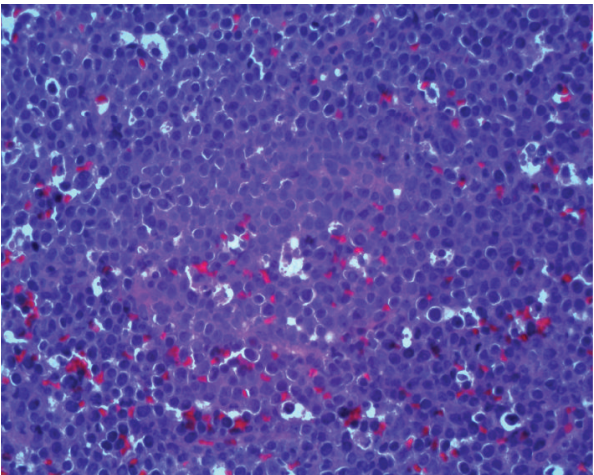

(a)

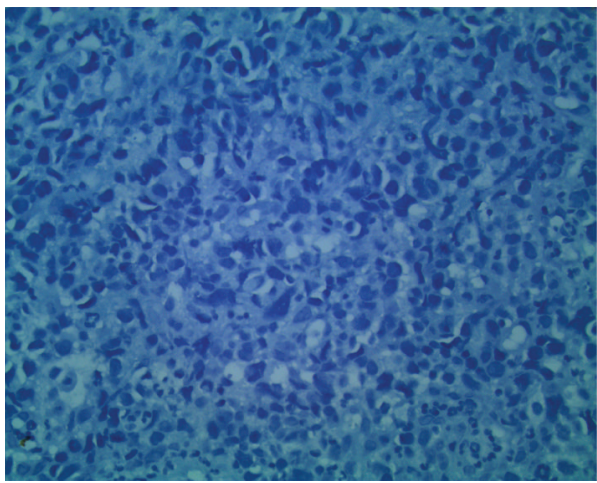

(c)

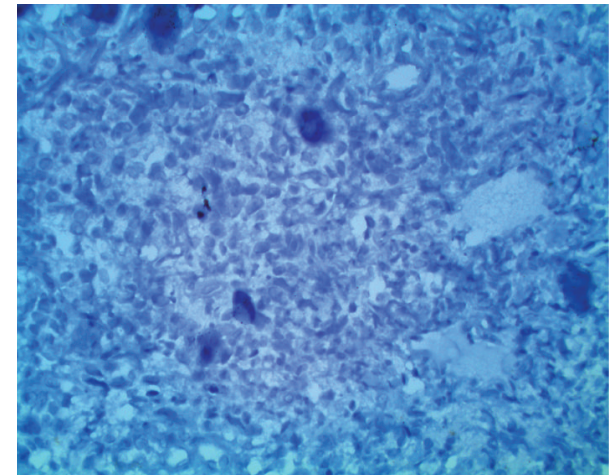

(b)

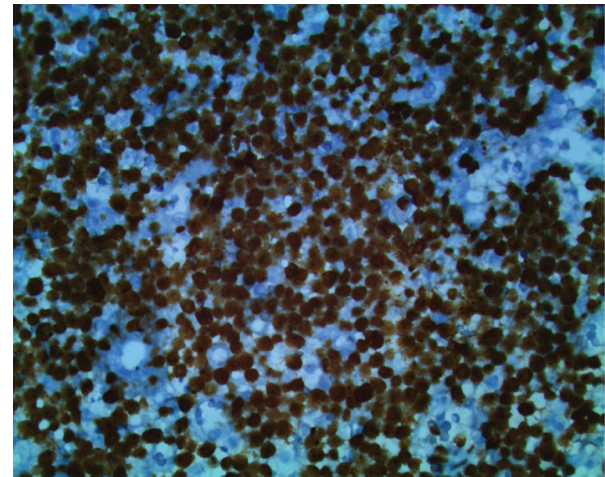

(d)

FIGURE 2: H\&E and immunohistochemical features of Patient 6. (a) H\&E compared to patient 1, the neoplastic cells are more homogeneous with respect to nuclear cytomorphology and sizes. They do not have the same nuclear eccentricity or nuclear heterochromatin pattern. (b) CD 20 stain is negative. (c) CD 138 stain is negative. (d) Ki-67 shows a high proliferative index (95-100\%).

TABLE 1: Clinical characteristics of seven patients with CD 20 negative aggressive B-cell lymphoma.

\begin{tabular}{|c|c|c|c|c|c|c|c|c|c|c|c|}
\hline & $\begin{array}{c}\text { Age } \\
\text { (years) }\end{array}$ & Sex & $\begin{array}{l}\text { WHO lymphoma } \\
\text { subtype }\end{array}$ & $\begin{array}{l}\text { HIV } \\
\text { status }\end{array}$ & $\begin{array}{l}\text { CD4 count } \\
(/ \mu \mathrm{l})\end{array}$ & Stage & $\mathrm{LDH}$ & $\begin{array}{l}\text { IPI } \\
\text { score }\end{array}$ & $\begin{array}{l}\text { Primary } \\
\text { therapy }\end{array}$ & Salvage therapy & $\begin{array}{l}\text { Survival } \\
\text { (months) }\end{array}$ \\
\hline (1) & 49 & M & Plasmablastic & + & 250 & IIE & Elevated & 1 & R-CHOP & $\mathrm{n} / \mathrm{a}$ & $36^{*}$ \\
\hline (2) & 47 & M & Plasmablastic & + & 106 & IVB & Elevated & 3 & R-CHOP & $\mathrm{n} / \mathrm{a}$ & $<1$ \\
\hline (3) & 37 & M & Plasmablastic & + & 45 & IVA & Normal & 1 & CHOP & $\mathrm{n} / \mathrm{a}$ & $24^{*}$ \\
\hline (4) & 33 & M & Plasmablastic & + & 84 & IVB & Elevated & 2 & Hyper-CVAD & $\mathrm{n} / \mathrm{a}$ & $24^{*}$ \\
\hline (5) & 42 & M & Plasmablastic & + & 47 & IVA & Elevated & 4 & None & none & $<1$ \\
\hline (6) & 44 & M & BCL-U & - & $\mathrm{n} / \mathrm{a}$ & IVB & Elevated & 3 & $\mathrm{CHOP}$ & Hyper-CVAD/ICE & 6 \\
\hline (7) & 40 & $\mathrm{~F}$ & BCL-U & - & $\mathrm{n} / \mathrm{a}$ & IVB & Elevated & 2 & $\mathrm{CHOP}$ & DHAP & 8 \\
\hline
\end{tabular}

M: male, F: female, BCL-U: B cell lymphoma unclassifiable, n/a: not applicable, LDH: lactate dehydrogenase, IPI: international prognostic index, ${ }^{*}$ still alive.

TABLE 2: Immunophenotypic features of patients with plasmablastic DLBCL.

\begin{tabular}{ccccccccccc}
\hline & CD20 & CD79 & Ki-67 & CD10 & Bcl-6 & Bcl-2 & CD138 & EBV & FISH for MYC/IgH \\
\hline$(1)$ & - & + & $40 \%$ & - & + & - & + & n/a & n/a \\
$(2)$ & - & + & $100 \%$ & - & - & - & + & n/a & n/a \\
$(3)$ & - & + & $85 \%$ & + & n/a & - & + & - & - \\
$(4)$ & - & n/a & $100 \%$ & + & - & - & + & + & + \\
$(5)$ & - & n/a & n/a & - & n/a & n/a & + & + & + \\
\hline
\end{tabular}

n/a: not available; -: negative; +: positive. 
$+\operatorname{add}(7)(\mathrm{q} 21),+8, \operatorname{add}(8)(\mathrm{q} 24),+9,+9,+9,+10,+11,+11$, $+\operatorname{del}(12)(\mathrm{q} 12),+\operatorname{del}(12)(\mathrm{q} 12),+13, \operatorname{add}(14)(\mathrm{q} 32)$ $\operatorname{add}(14)(\mathrm{q} 32), \operatorname{add}(14)(\mathrm{q} 32),+15,+15,+16,+\operatorname{del}(17)(\mathrm{p} 12)$, $+18,+19,+19,+20,+20,+21,+22,+22$.

FISH probes did not show classical MYC/IgH translocation. However, an extra copy of c-myc was detected. Bcl2 was not rearranged. According to the 2008 world health organization (WHO) classification, this tumor best fit in the category B-cell lymphoma unclassifiable (BCLU) with features intermediate between diffuse large B-cell lymphoma and Burkitt's lymphoma.

The tumor was primary refractory and did not respond to R-CHOP, hyper CVAD, or R-ICE (ifosfamide, carboplatin, and etoposide). Patient died six months after diagnosis.

Patient 7 was a 40 -year-old HIV negative female who presented with a 20 pound weight loss, night sweats and extensive retroperitoneal, and mediastinal and axillary adenopathy. Biopsy of a retroperitoneal node showed a large Bcell lymphoma. By immunohistochemistry, tumor cells were positive for CD 79a, CD10, and bcl-6. Ki 67 was close to $100 \%$. Tumor did not express CD 20, bcl-2, or CD 5. Bone marrow was infiltrated by lymphoma. Flow cytometry confirmed the lymphoma did not express CD 20.

She received 8 cycles of $\mathrm{CHOP}$ with a partial response. She relapsed 1 month after the last cycle. She then received salvage therapy with dexamethasone, high dose cytarabine, and cisplatin (DHAP). She had progressive disease by the second cycle and died nine months after initial diagnosis.

\section{Discussion}

Our study suggests that the largest proportion (71.4\%) of CD 20 negative diffuse large B-cell lymphomas encountered in clinical practice are likely to be plasmablastic variants. These tumors are characterized by acquisition of the transcription profile of plasma cells, with extinction of B-cell differentiation program. Hence, they do not express common B-cell markers like CD 20 and CD79a while expressing plasma cell markers like CD 38, CD 138, and Mum1 [6, 8].

The clinical features (male predominance, median age in early-to-mid 40s, predilection for extra nodal involvement, higher stage at diagnosis, high IPI, bone marrow involvement, and CD 4 count $<200 / \mu \mathrm{L}$ ) of our patients with HIV associated plasmablastic DLBCL are consistent with other reported studies [9-11]. Of the 4 patients who received treatment, 3 responded and are in remission at median followup of 2 years. This is in contrast to other more recent reported studies of HIV-associated plasmablastic lymphoma, where the median survival is in order of 11-15 months $[12,13]$. Although our patients had a low CD 4 count at presentation, their IPI score was low to low intermediate and they were treated with concurrent antiretroviral therapy. This may account for the better survival, however, given the small number of patients in our study $(n=5)$ we suggest caution in drawing any specific conclusions. Use of antiretroviral therapy, CD 4 count at presentation, IPI score, performance status, and achievement of a complete response to chemotherapy have been reported to affect prognosis [1214].

Two additional subtypes of DLBCL, ALK (anaplastic lymphoma kinase) positive DLBCL and primary effusion lymphoma, also have plasmablastic features and do not express CD $20[15,16]$. These are extremely rare subtypes and we did not find any patients with these variants in our series.

We identified 2 patients with unclassifiable B-cell lymphoma which was CD 20 negative. Patient 6 had an aggressive, B-cell lymphoma with high proliferation index. An extremely complex karyotype was identified which included a gain of myc oncogene. These findings are consistent with a BCLU with features intermediate between DLBCL and Burkitt's lymphoma [17, 18].

Patient 7 also had an aggressive B-cell lymphoma with Ki 67 of $100 \%$. By flow cytometry and immunohistochemistry, the tumor did not express CD 20. It had a germinal center immune-phenotype (CD 10-positive and bcl-6 positive) which argues against it being a plasmablastic DLBCl which usually have an activated B-cell phenotype [13].

BCLU is a heterogeneous disease category. It was introduced in the $2008 \mathrm{WHO}$ classification to capture aggressive lymphomas which have overlapping features of DLBCL and Burkitt's lymphoma, but do not meet the criteria of either of these more specifically defined entities [17]. Many studies have suggested that a large proportion of BCLU have both myc and bcl-2 translocations. We reviewed the immunophenotypic features of published case series on these "dual hit" lymphomas [19-24]. None of the reported cases had a CD 20 negative phenotype. Our patient had an extremely complex karyotype and had an extra copy of c-myc oncogene, without myc or bcl-2 translocation. This genetic complexity may account for the discrepancy noted in the immunophenotype and may suggest a different subtype of BCLU.

Consistent with other reported series, both of the above patients responded poorly to standard (CHOP) and aggressive (Hyper-CVAD, DHAP) chemotherapy [18, 19]. The immunomodulatory agent, lenalidomide and the proteasome inhibitor, and bortezomib have recently been reported to be active in a specific molecular subtype of DLBCL, the activated-B cell like DLBCL $[25,26]$. There is an urgent need to study these and other novel biologic agents in BCL-U.

\section{Conclusions}

Most cases of CD 20 negative DLBCL encountered in clinical practice are likely to be plasmablastic variants of large B-cell lymphoma. However, a small minority of BCLU may also lack CD 20 expression. These unclassifiable lymphomas may not have the commonly described rearrangements in myc and bcl-2 oncogenes however share the same dismal prognosis. Further studies with larger number of patients are required to confirm this finding.

\section{References}

[1] L. M. Morton, S. S. Wang, S. S. Devesa, P. Hartge, D. D. Weisenburger, and M. S. Linet, "Lymphoma incidence patterns by WHO subtype in the United States, 1992-2001," Blood, vol. 
107, no. 1, pp. 265-276, 2006.

[2] B. Coiffier, E. Lepage, J. Brière et al., "Chop chemotherapy plus rituximab compared with chop alone in elderly patients with diffuse large-B-cell lymphoma," The New England Journal of Medicine, vol. 346, no. 4, pp. 235-242, 2002.

[3] R. Pettengell and D. Linch, "Position paper on the therapeutic use of rituximab in CD20-positive diffuse large B-cell nonHodgkin's lymphoma," British Journal of Haematology, vol. 121, no. 1, pp. 44-48, 2003.

[4] W. E. Paul, Fundamental Immunology, Lippencott Williams \& Wilkins, Philadelphia, Pa, USA, 6th ed edition, 2008.

[5] S. Montes-Moreno, C. Montalban, and M. A. Piris, "Large B-cell lymphomas with plasmablastic differentiation: a biological and therapeutic challenge," Leukemia \& Lymphoma, vol. 53, no. 2, pp. 185-194, 2012.

[6] E. D. His, R. B. Lorsbach, F. Fend, and A. Dogan, "Plasmablastic lymphoma and related disorders," American Journal of Clinical Pathology, vol. 136, pp. 183-194, 2011.

[7] C. Laurent, C. Do, R. D. Gascoyne et al., "Anaplastic lymphoma kinase-positive diffuse large B-cell lymphoma: a rare clinicopathologic entity with poor prognosis," Journal of Clinical Oncology, vol. 27, no. 25, pp. 4211-4216, 2009.

[8] J. J. Castillo and J. L. Reagan, "Plasmablastic lymphoma: a systematic review," Scientific World Journal, vol. 11, pp. 687-696, 2011.

[9] J. Teruya-Feldstein, E. Chiao, D. A. Filippa et al., "CD20negative large-cell lymphoma with plasmablastic features: a clinically heterogenous spectrum in both HIV-positive and negative patients," Annals of Oncology, vol. 15, no. 11, pp. 1673-1679, 2004.

[10] L. Colomo, F. Loong, S. Rives et al., "Diffuse large B-cell lymphomas with plasmablastic differentiation represent a heterogeneous group of disease entities," American Journal of Surgical Pathology, vol. 28, no. 6, pp. 736-747, 2004.

[11] J. J. Castillo, E. S. Winer, D. Stachurski et al., "Clinical and pathological differences between human immunodeficiency virus-positive and human immunodeficiency virus-negative patients with plasmablastic lymphoma," Leukemia and Lymphoma, vol. 51, no. 11, pp. 2047-2053, 2010.

[12] J. J. Castillo, M. Furman, B. E. Beltran et al., "Human immunodeficiency virus-associated plasmablastic lymphoma: poor prognosis in the era of highly active antiretroviral therapy," Cancer, vol. 118, no. 21, pp. 5270-5277, 2012.

[13] J. Castillo, L. Pantanowitz, and B. J. Dezube, "HIV-associated plasmablastic lymphoma: lessons learned from 112 published cases," American Journal of Hematology, vol. 83, no. 10, pp. 804-809, 2008.

[14] J. J. Castillo, E. S. Winer, D. Stachurski et al., "Prognostic factors in chemotherapy-treated patients with HIV-associated plasmablastic lymphoma," Oncologist, vol. 15, no. 3, pp. 293-299, 2010.

[15] R. D. Gascoyne, L. Lamant, J. I. Martin-Subero et al., "ALKpositive diffuse large B-cell lymphoma is associated with Clathrin-ALK rearrangements: report of 6 cases," Blood, vol. 102, no. 7, pp. 2568-2573, 2003.

[16] R. G. Nador, E. Cesarman, A. Chadburn et al., "Primary effusion lymphoma: a distinct clinicopathologic entity associated with the Kaposi's sarcoma-associated herpes virus," Blood, vol. 88, no. 2, pp. 645-656, 1996.

[17] S. H. Swerdlow, E. Campo, N. L. Harris et al., WHO Classification of Tumours of Haematopoietic and Lymphoid Tissues, IARC press, Lyon, France, 2008.
[18] I. Salaverria and R. Siebert, “The gray zone between Burkitt's lymphoma and diffuse large B-cell lymphoma from a genetics perspective," Journal of Clinical Oncology, vol. 29, no. 14, pp. 1835-1843, 2011.

[19] S. Le Gouill, P. Talmant, C. Touzeau et al., "The clinical presentation and prognosis of diffuse large B-cell lymphoma with $\mathrm{t}(14 ; 18)$ and 8q24/c-MYC rearrangement," Haematologica, vol. 92, no. 10, pp. 1335-1342, 2007.

[20] N. Tomita, M. Tokunaka, N. Nakamura et al., "Clinicopathological features of lymphoma/leukemia patients carrying both BCL2 and MYC translocations," Haematologica, vol. 94, no. 7, pp. 935-943, 2009.

[21] N. Niitsu, M. Okamoto, I. Miura, and M. Hirano, "Clinical features and prognosis of de novo diffuse large B-cell lymphoma with $\mathrm{t}(14 ; 18)$ and $8 \mathrm{q} 24 / \mathrm{c}-\mathrm{MYC}$ translocations," Leukemia, vol. 23, no. 4, pp. 777-783, 2009.

[22] A. Kanungo, L. J. Medeiros, L. V. Abruzzo, and P. Lin, "Lymphoid neoplasms associated with concurrent $\mathrm{t}(14 ; 18)$ and 8q24/c-MYC translocation generally have a poor prognosis," Modern Pathology, vol. 19, no. 1, pp. 25-33, 2006.

[23] M. Snuderl, O. K. Kolman, Y. B. Chen et al., "B-cell lymphomas with concurrent IGH-BCL2 and MYC rearrangements are aggressive neoplasms with clinical and pathologic features distinct from burkitt lymphoma and diffuse large B-cell lymphoma," American Journal of Surgical Pathology, vol. 34, no. 3, pp. 327-340, 2010.

[24] N. A. Johnson, K. J. Savage, O. Ludkovski et al., "Lymphomas with concurrent BCL2 and MYC translocations: the critical factors associated with survival," Blood, vol. 114, no. 11, pp. 2273-2279, 2009.

[25] F. G. Hernandez-llizaliturri, G. Deeb, P. L. Zinzani et al., "Higher response to lenalidomide in relapsed/refractory diffuse large B-cell lymphoma in non germinal center B-cell likethan in germinal center B-cell like phenotype," Cancer, vol. 117, pp. 5058-5066, 2011.

[26] K. Dunleavy, S. Pittaluga, M. S. Czuczman et al., "Differential efficacy of bortezomib plus chemotherapy within molecular subtypes of diffuse large B-cell lymphoma," Blood, vol. 113, no. 24, pp. 6069-6076, 2009. 


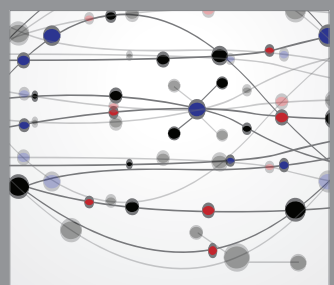

The Scientific World Journal
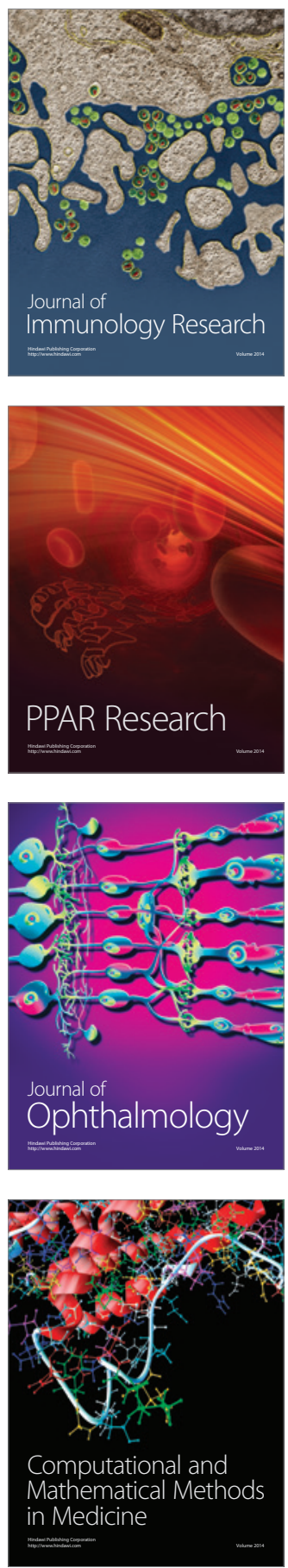

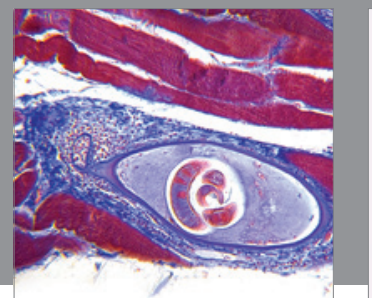

Gastroenterology

Research and Practice
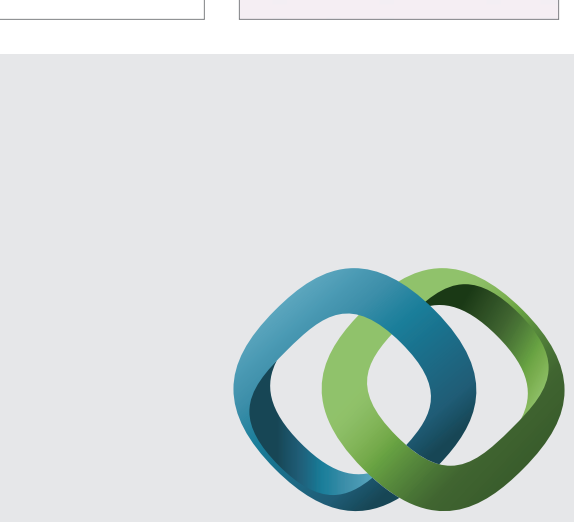

\section{Hindawi}

Submit your manuscripts at

http://www.hindawi.com
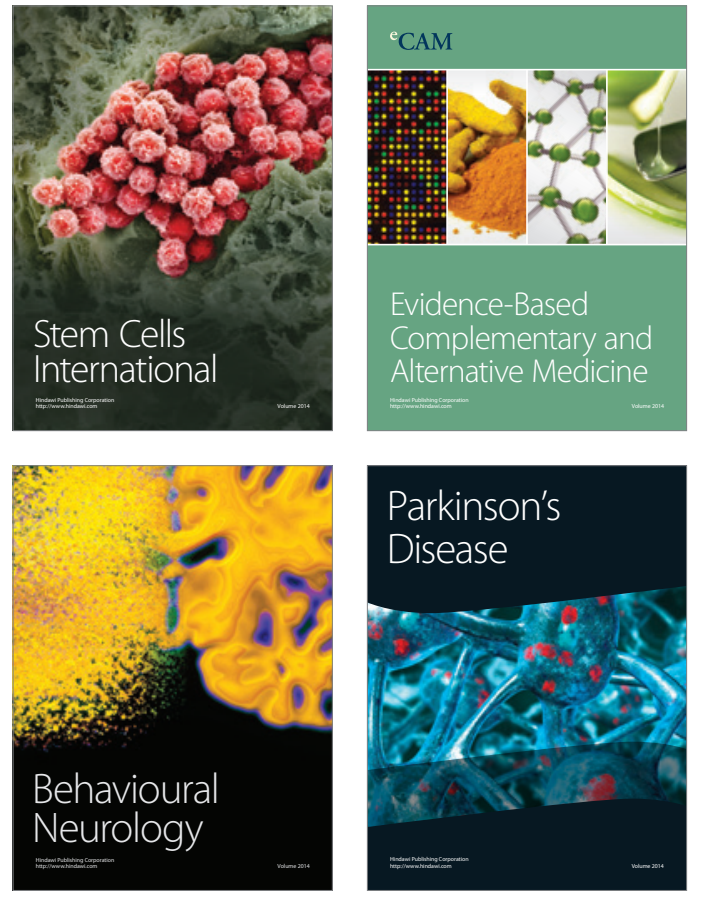
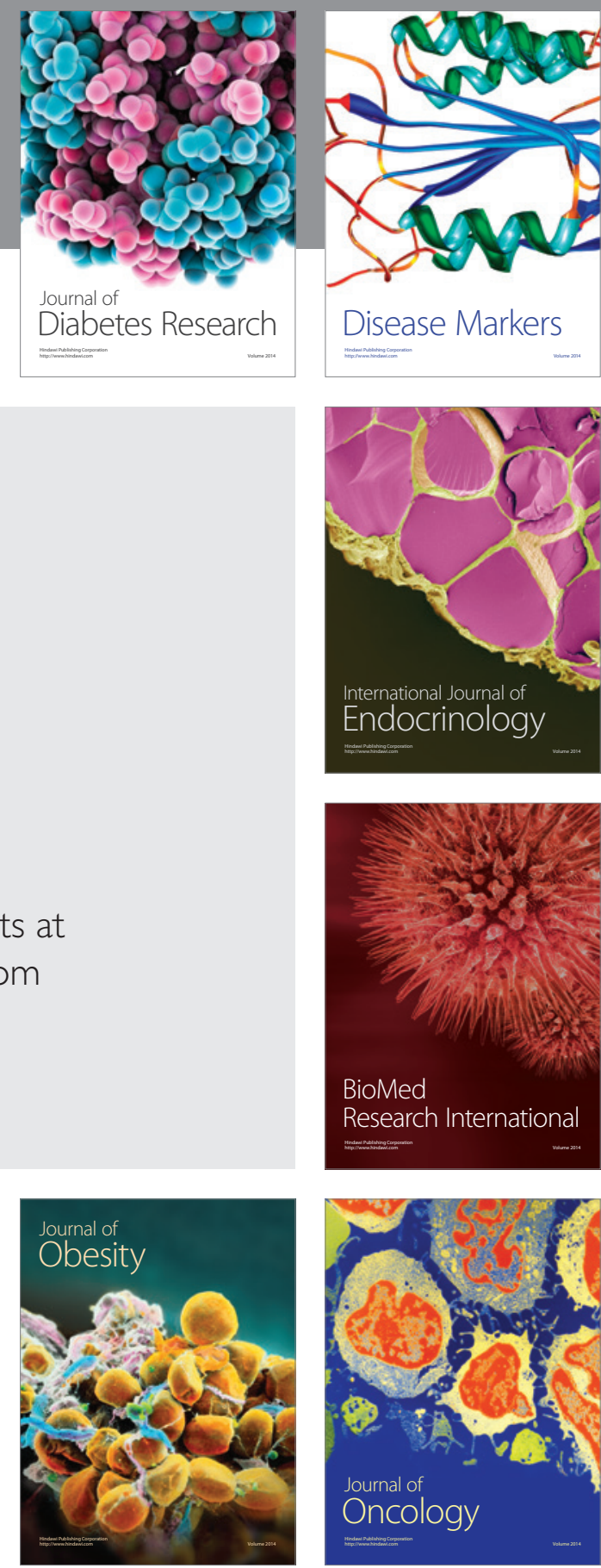

Disease Markers
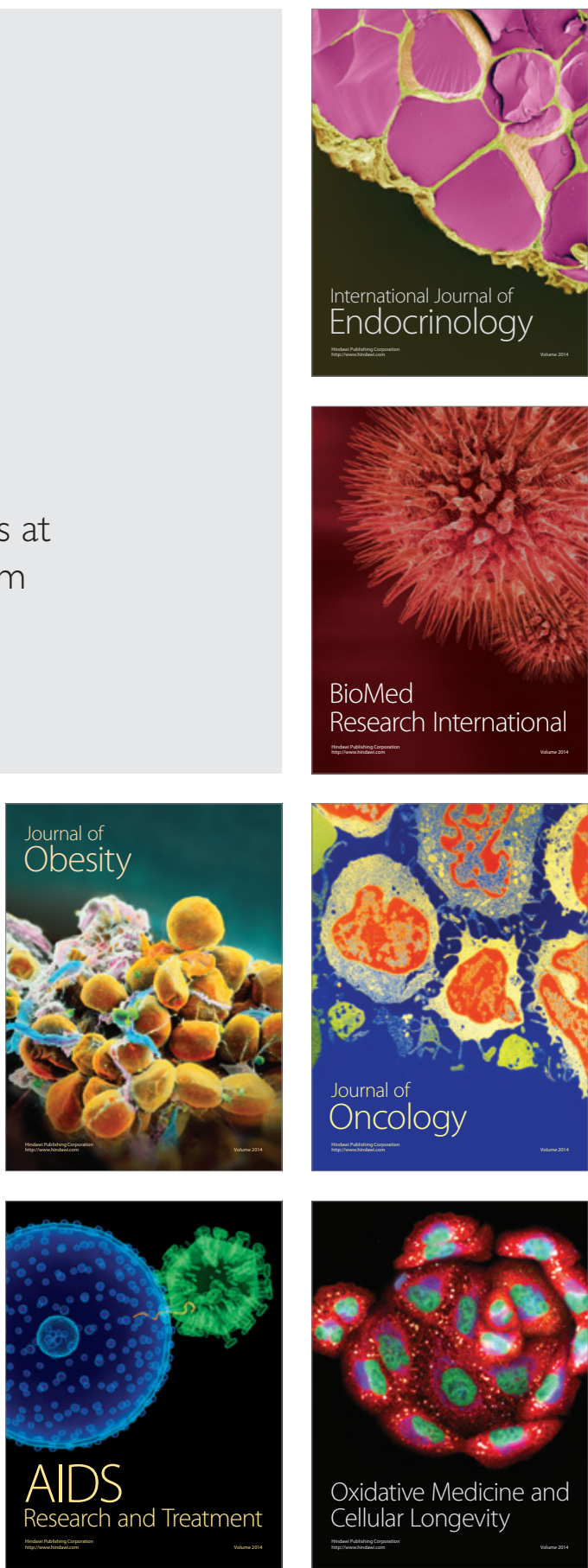